\title{
AMN-2 to Be Held in New Zealand in February 2005
}

The Second International Conference on Advanced Materials and Nanotechnology (AMN-2) will be hosted by the MacDiarmid Institute for Advanced Materials and Nanotechnology, a New Zealand Centre of Research Excellence, February 6-11, 2005. The conference will be held in Queenstown, New Zealand, and is organized by committee chair Steven M. Durbin and program chair Richard Blaikie, both of the University of Canterbury in Christchurch.

The purpose of the conference is to promote international collaborations in the broad areas of advanced materials and nanotechnology, with a particular emphasis on new and emerging technologies. Technical symposia will include bio- molecular assembly, conducting polymers, functional materials, nanoengineered materials and devices, nanolithography, nanoscale optics, nanotube growth and device concepts, novel semiconductor materials, physics of clusters and clusterbased devices, and properties of superconducting materials.

More than 30 invited speakers have agreed to participate, including Nobel Laureates Alan MacDiarmid (Pennsylvania State University, USA) and Klaus von Klitzing (Max-Planck-Institut für Festkörperforschung, Germany). The conference will encompass over two days of plenary talks and two days of parallel sessions. Proceedings will be published as a special issue of Current Applied Physics.
The conference is endorsed by the Materials Research Society. Sponsors include Raith $\mathrm{GmbH}$, the Royal Society of New Zealand, and the Foundation for Research, Science, and Technology.

Located on the South Island of New Zealand, Queenstown is a popular tourist destination close to many outdoor activities. February is summer in New Zealand, an ideal time for sightseeing before or after the conference.

For more information, contact the conference office at the Centre for Continuing Education, University of Canterbury, Private Bag 4800, Christchurch, New Zealand; tel. 64-3-364-2534; fax 64-3-3642324; e-mail amn2@cont.canterbury.ac.nz; or access Web site www.macdiarmid.ac. $\mathrm{nz} / \mathrm{amn}-2$.

\section{MRS Awards}

It's Not Too Early to Think About the MRS Awards Program!

DEADLINE for NominationsJune 1, 2005

The MRS Awards Program acknowledges outstanding contributors to the progress of materials research, and recognizes their exciting and profound accomplishments. A variety of awards are offered to honor those whose work has already had a major impact in the field, those who have defined the frontiers of the field, and those who are outstanding exponents of their science.

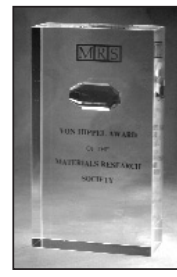

\section{VON HIPPEL AWARD}

The Von Hippel Award, the Society's highest honor, recognizes those qualities most prized by materials scientists and engineers - brilliance and originality of intellect, combined with vision that transcends the boundaries of conventional scientific disciplines. Presented annually at the MRS Fall Meeting, and named in honor of its first recipient, the Von Hippel Award includes a cash honorarium and a unique trophy - a mounted ruby laser crystal symbolizing the many-faceted nature of materials science.

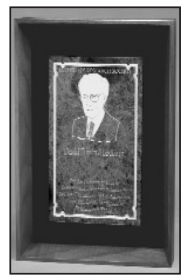

\section{DAVID TURNBULL LECTURESHIP}

The purpose of this lectureship is to recognize the career of a scientist who has made outstanding contributions to understanding materials phenomena and properties through research, writing, and lecturing, as exemplified by the life work of David Turnbull. It also provides lectures of exceptional quality and scientific significance for the MRS Fall Meeting as well as, possibly, MRS Section and University Chapter meetings. Recipients of this award receive a cash honorarium and a citation plaque.

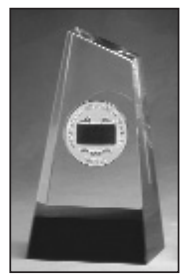

\section{MRS MEDAL AWARD}

MRS Medals are intended to constitute public and professional recognition of outstanding recent achievements in materials research. An engraved medal and citation certificate are awarded, along with a cash honorarium, for a specific discovery or advancement which is expected to have a major impact on the progress of any materials-related field.

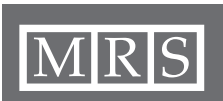

For more information on the MRS Awards

Program and the

nomination

procedure,

visit

www.mrs.org/awards/ 